\title{
WATERPROOF PROCESS IN FOOTWEAR INDUSTRY
}

\author{
ADRIANA CHIRILĂ, ALINA IOVAN-DRAGOMIR \\ "Gheorghe Asachi" Technical University of Iasi, Faculty of Textiles, Leather and Industrial \\ Management, 28 D. Mangeron, Iasi, Romania, Adriana8chirila@gmail.com, \\ adragomir@tex.tuiasi.ro (corresponding author)
}

\begin{abstract}
Waterproofing is the ability to prevent water from entering and has been a concern for people long before the invention of modern substances, chemicals or technologies. This paper presents water proof process in footwear industry. The paper has three parts: introduction, case study and conclusion. In the first part, are presented two popular methods to provide protection against water for shoes. In the footwear industry the usual methods of waterproofing are by adding a waterproof bootie inside the shoes or by attaching a protective membrane on the semi-finished uppers. Both methods have gathered quite a following among users and both promise to protect the user in harsh conditions, but also offer breathability and comfort. These waterproofing methods are the OutDry ${ }^{\circledR}$ and Gore-Tex ${ }^{\circledR}$ technologies. In the second part, it is presented a case study; it is analyse waterproof for defected pair a hiking boots constructed using OutDry Technology. In order, it was use 2 testing methods: centrifuge test and dynamic footwear water penetration test. In conclusion, waterproofing footwear using innovative methods and processes can be challenging and manufacturers need to adapt and evolve in order to comply with the standards. But difficulties are not a deterrent; they represent opportunities to become better professionals, more knowledgeable users of technology and a more conscious industry on the environmental impact of footwear manufacturing processes.
\end{abstract}

Keywords: footwear, waterproof, technology.

\section{INTRODUCTION}

Ages before the use of special processes and technology, humans used substances found in nature to gift everyday objects with waterproof qualities. On naval ships, tar and pitch were the main methods for sealing the hulls of boats. These materials were sealing all the wooden connections of the vessel together, keeping the water out. Oil was another trick sailors had in the sixteenth century; back then sails were greased with oil to ensure that the fabric could withstand the difficult sea environment and intense storms. The use of common bees wax began to rise in popularity as a waterproofing method around the end of the nineteenth century. In the clothing industry wax-covered threads could be weaved into somewhat waterproof garments and leather footwear was rubbed and coated with bees wax or animal fat to make it impermeable to water. All of these past forms of waterproofing, by tar, oil, wax, or animal fat aimed at a common goal, of keeping water out and the people using those objects dry and comfortable.

Coming into more modern times, waterproofing has been adapted and new technologies have emerged and evolved. In the footwear industry the usual methods of waterproofing are by adding a waterproof bootie inside the shoes or by attaching a protective membrane on the semi-finished uppers. Both methods have gathered quite a following among users and both promise to protect the user in harsh conditions, but also offer breathability and comfort. Two main representatives of these waterproofing methods are the OutDry ${ }^{\mathbb{B}}$ and Gore-Tex ${ }^{\mathbb{B}}$ technologies.

\section{OutDry ${ }^{\circledR}$ Technology}

OutDry ${ }^{\circledR}$ is an innovative construction process that can be used to make gloves, backpacks and footwear completely waterproof yet breathable. The patented method 
does not leave seams or gaps because the fabric layers are heat-bonded together. In this case the binding process becomes more important that the material itself because it helps fabrics achieve optimum water-resistance. Without space between the impenetrable waterproof complex and the fabrics that make the uppers, water is not able to permeate the layers and get trapped in the footwear. This construction assures that there is no chance for the water to leak through the fabric after long exposures to wet environments. This method of applying the membrane does not affect the breathability of materials (Figure 1).

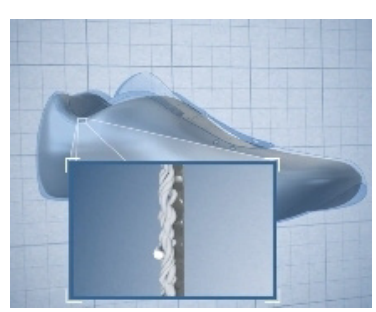

Figure 1. Applying OutDry ${ }^{\circledR}$ membrane to footwear uppers

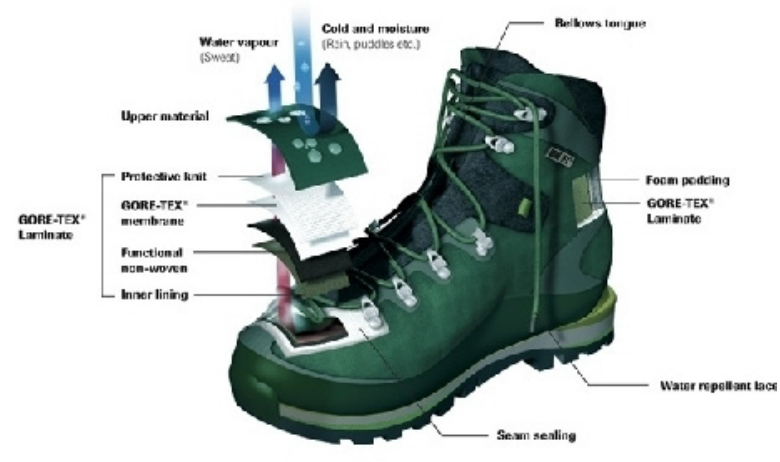

Figure 2. Gore-Tex ${ }^{\circledR}$ Technical details

OutDry ${ }^{\circledR}$ fabrics have an advantage point in the fact that they do not require the use of durable water repellent or DWR coatings, which most of times are not environmentally friendly and need many years to breakdown, while causing a lot of harm to the environment in the process.

\section{Gore-Tex $^{\circledR}$ Technology}

Gore-Tex $^{\circledR}$ is a special material made of PTFE (Polytetrafluoroethylene) a hydrophobic compound, is a microporous material with a very low water-adsorption rate and also extremely durable. It is commonly known as Gore-Tex ${ }^{\circledR}$ fabric and it was developed and patented by the brand with the same name (Figure 2).

The Gore-Tex ${ }^{\circledR}$ fabric can be analyzed from three main perspectives as a membrane, a laminate and a fabric technology.

- Gore-Tex $^{\circledR}$ is considered a membrane because it contains over 9 billion breathable pores per square inch, which is why it allows for moisture transfer from the interior of the shoes towards the exterior and away from the body.

- The material is also viewed a laminate because it is bonded between the outer and inner linings and creates a single layer with all three elements working as one.

- And finally, it is considered a fabric technology because it comes in roles and can be tailored for different products with diverse construction requirements and maintains its waterproof and highly breathable qualities. 
OutDry $^{\circledR}$ versus Gore-Tex ${ }^{\circledR}$

Looking at the qualities of these fabrics a comparison can be made on a technical level. Considering the waterproof rating both technologies claim to be fully waterproof. Fabrics with a water column of $10.000 \mathrm{~mm}$ and higher are considered to be fully waterproof. Diverse waterproof fabrics behave differently and not all withstand water pressure at the same level.

In this matter OutDry ${ }^{\circledR}$ has a rating of around $20.000 \mathrm{~mm}$, passing the water column test, making it fully waterproof.

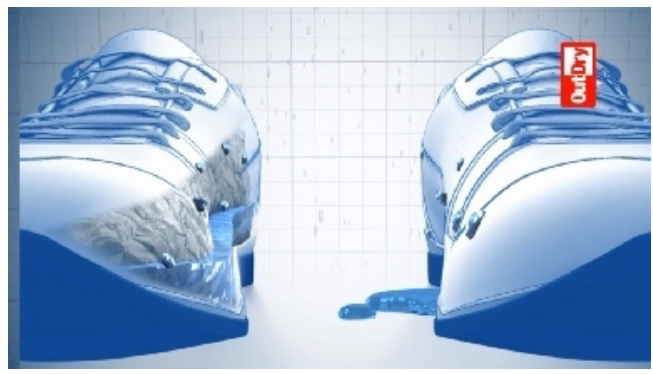

Figure 3. Footwear construction: a). Waterproof Gore-Tex® type construction with bootie; b). OutDry® membrane lamination

Gore-Tex $^{\circledR}$, by comparison, starts at $28.000 \mathrm{~mm}$ and can go above that value for certain products, making it considerably more adapted than OutDry ${ }^{\circledR}$ to withstand heavy water conditions. However, there is another element to be taken into consideration with the Gore-Tex ${ }^{\circledR}$ technology, the use of DWR (durable water repellant) coatings.

OutDry ${ }^{\mathbb{B}}$ is a two-layer fabric, bound together by a heat source. There is no need for DWR treatments to protect the shoes in harsh water conditions because it leaves no gaps in between the layers and the uppers are fully waterproof. Gore-Tex ${ }^{\mathbb{B}}$, on the other hand, utilizes DWR treatments to minimize water contact and this helps further waterproof the fabric.

If only the water columns levels are analyzed then Gore-Tex ${ }^{\circledR}$ is in advantage, but considering the water resistance capabilities in time then OutDry ${ }^{\circledR}$ comes as the superior choice because DWR coatings tend to degrade overtime. This degradation makes the shoes more vulnerable to bad weather conditions and also gives them a tendency to overheat, due to the pores clogging from the water. Usually the DWR coatings and treatments require regular maintenance so that the footwear keeps up its protective qualities against the weather. DWR treatments are also concerning for their environmental impact and health issues they might produce because of PFCs (Perfluorinated compounds). Member compounds of this large chemical family are linked to several types of tumors and neonatal deaths and toxicity in the liver and endocrine system, as stated by EU research and the United States Environmental Protection Agency. This is why major sports brands are beginning to use PFC-free materials when waterproofing their products.

When comparing these two materials one of the most important qualities, breathability, must be taken into account in order to avoid overheating and excessive sweating during footwear usage. On this point, OutDry ${ }^{\circledR}$ provides an adequate level of 
breathability, keeping moisture away from the body. However it has been showed that it has a tendency to overheat, more than the Gore-Tex ${ }^{\circledR}$ option.

\section{QUALITY EVALUATION FOR A DEFECTIVE PAIR OF HIKING BOOTS CONSTRUCTED WITH OUTDRY WATERPROOF TECHNOLOGY (CASE STUDY)}

Before proceeding to the quality evaluation of a defective pair of hiking boots constructed with the OutDry ${ }^{\circledR}$ waterproof technology, must be stated the fact that these shoes are not branded by the company in question.

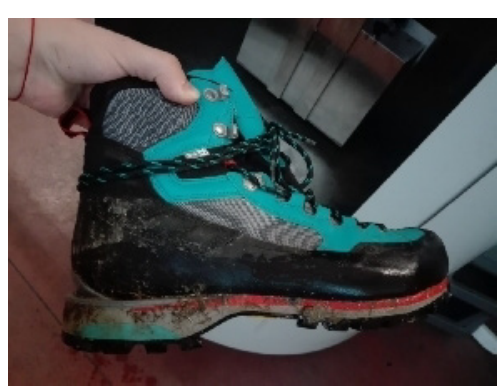

Figure 4. Footwear sample with waterproof issues (personal archive)

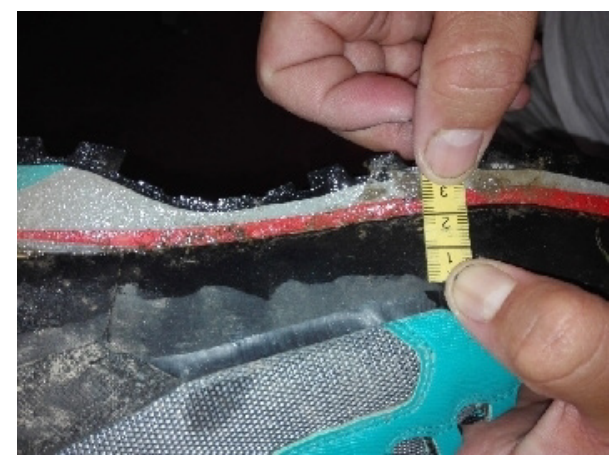

Figure 5. Water level in the tank (personal archive)

In fact several shoe manufacturers have acquired the legal rights to use this technology and produce waterproof footwear under the directions and process standards patented by OutDry ${ }^{\circledR}$. The quality and performance of the footwear often depends on the manufacturers capacities of implementing and following the process standard.

The article (Figure 4) under consideration is a pair of woman hiking boots that was returned by the user for waterproof issues. The general state of the shoe showed clear signs of use with water stains and mud debris reaching the collar. There were no evident puncture marks, torn or unstitched material on the exterior of the shoe.

The first test to be performed was the centrifuge test. The test was performed following the OutDry ${ }^{\circledR}$ standard OUTDRY OS - 05, version 1. Similar to a static footwear water penetration test, the shoes were placed and secured in a water tank where the water level was set for $2 \mathrm{~cm}$ above the flexion point of the sole (Figure 5). Tray centrifugation was set for 250 rotation per miute for the duration of 10 minutes. The insock of the shoes was wrapped in paper with high water absorption qualities and inserted back in the tested footwear.

After analyzing the output for the centrifuge machine, no water penetration marks were observed inside the footwear concluding that the tested pair passed the centrifuge test.

The second test to be performed was a dynamic footwear water penetration test, using a machine mimicking the foot movement and flexion of the metatarsophalangeal joint. The pneumatic machine used for testing was a SATRA STM 505 model, a 
Dynamic Footwear resistance Tester, commonly found in testing laboratories for water resistance tests.

The internal manufacturer requirements set for waterproof footwear in the dynamic water penetration test is a value of 50000 flexion correlated to moderate use of the hiking footwear in the terrain it was designed for. The tested pair of hiking boots failed this requirement because water marks could be observed on the insock paper after 4000 flexion.

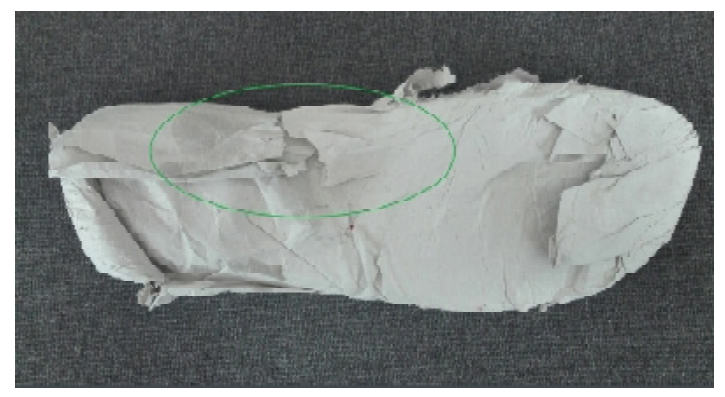

Figure 6. Water stains in the paper insock after 4000 flexion on the Dynamic Footwear Resistance Machine (personal archive)

The following step was to cut open the failed sample and analyze the internal components affecting the waterproof parameters: the OutDry ${ }^{\circledR}$ membrane, the gasket and the aquablock tape. The shoe was cut in half from toe to heel displaying a transversal image of its construction.

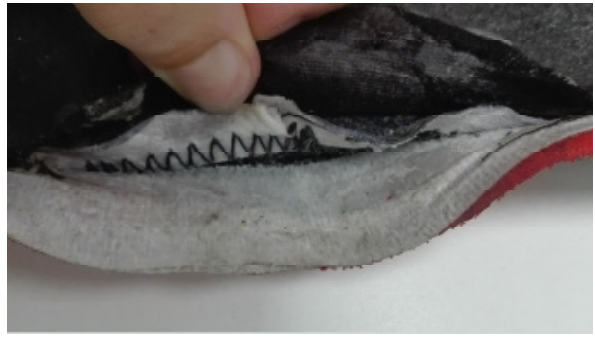

Figure 7. The aquablock overlap and stitching forming a hard point (personal archive)

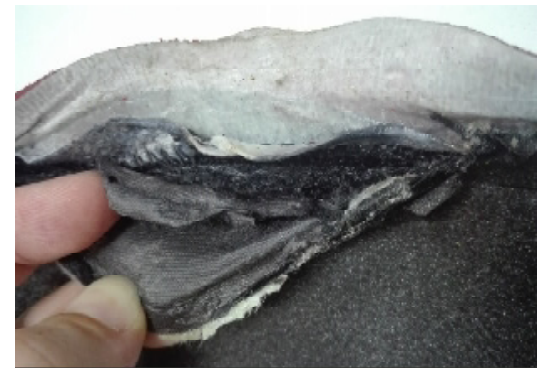

Figure 8. Two overlapped OutDry ${ }^{\circledR}$ membranes identified in the tested pair of hiking boots (personal archive)

The water penetration point was identified on the medial lateral inside if the shoe, where the ends of the aquablock tape overlap (Figure 7). It was noted that the finishing overlap of the tape was of $6 \mathrm{~mm}$ when the requirements are set for $7-15 \mathrm{~mm}$. Also the reinforcement stitching formed a hard point in the area. Other remarks referred to the gasket that was correctly placed, covering the stitching completely and the aquablock tape, which was straight without wrinkles.

Further research was necessary in order to identify the direct cause of the failed waterproof issue. Under the effect of a heat gun, the layers of the uppers were separated. 
In doing so two layers of OutDry ${ }^{\circledR}$ membrane could be observed indicating that the shoe was previously repaired (Figure 8).

Going deeper into the issue it was revealed that the first membrane split in the counter area during the laminating process. Because removing the membrane could potentially cause damage to the uppers, the preferred solution was to add a second membrane to the shoe, leaving the first one in place. The overlapping thickness of the two membranes and the added material plus the inadequate stitching of the aquablock tape have combined and created a waterproof problem. At the same time the work process and the temperature parameters for OutDry ${ }^{\circledR}$ and gasket were not adapted to this situation that deviates from the standards.

What this case comes to prove is that the manufacturer using the waterproof technology must thoroughly assimilate the process knowledge before venturing into production. Constant evaluations of the work techniques must be made and direct supervision should be the norm for key working stations in the production line.

\section{CONCLUSION}

Traditional manufacturing methods have helped the footwear industry develop and are a great source of knowledge and experience. From household items have spurred innovative ideas that have thrusted the footwear production methods further into the future.

If only the water columns levels are analyzed then Gore-Tex ${ }^{\circledR}$ is in advantage, but considering the water resistance capabilities in time then OutDry ${ }^{\circledR}$ comes as the superior choice.

Waterproofing footwear using innovative methods and processes can be challenging and manufacturers need to adapt and evolve in order to comply with the standards. But difficulties are not a deterrent; they represent opportunities to become better professionals, more knowledgeable users of technology and a more conscious industry on the environmental impact of footwear manufacturing processes.

\section{REFERENCES}

Dragomir, A. (2009), "Materii prime pentru încălțăminte”, Editura Performantica, ISBN 978-973-730-476-6, Iași.

Marlocchi, A. (1998), U.S.Patent No.6855171B2, OutDry Technologies Corp.

Majbaur, R.K. (2015), "Study about polymer applications in footwear", Plastic Technology Arcada University of Applied Science, Finland.

***, Life cycle assessment of a pair of GORE-TEX ${ }^{\circledR}$ branded waterproof and breathable hiking boots.

***, https://www.scarpa.co.uk/technical/

$* * *$, https://www.gore-tex.com/technology/what-is-gore-tex.

$* * *$, https://patents.justia.com/patent/9315002

***, https://www.satra.com/test_equipment/machine.php?id=78 